\title{
Self-sterility May Be Due to Prezygotic Late-acting Self-incompatibility and Early-acting Inbreeding Depression in Chinese Chestnut
}

\author{
Huan Xiong and Feng Zou ${ }^{1}$ \\ The Key Laboratory of Cultivation and Protection for Non-wood Forest trees, Ministry of Education, \\ Central South University of Forestry and Technology, Changsha, Hunan, 410004, P.R. China
}

Sujuan Guo

Beijing Forestry University, Beijing, 100083, P.R. China

Deyi Yuan

The Key Laboratory of Cultivation and Protection for Non-wood Forest trees, Ministry of Education, Central South University of Forestry and Technology, Changsha, Hunan 410004, P.R. China

Genhua Niu

Texas AgriLife Research at El Paso, Texas A\&M University System, 1380 A\&M Circle, El Paso, $T X 79927$

\begin{abstract}
AdDitional INDEX words. abnormal pollen tubes, double fertilization, ovule aborted, ovary
Abstract. Chinese chestnut (Castanea mollissima), which is native to China, has been cultivated as a nontimber forest tree species for $\mathbf{4 0 0 0}$ years. This species has been found to display self-sterility, which results in a significantly lower seed set following self-pollination (SP) compared with that following cross-pollination (CP). Self-sterility can be induced by prezygotic or postzygotic late-acting self-incompatibility (LSI) or early-acting inbreeding depression (EID). To elucidate the causes of self-sterility in chestnut, we investigated pollen-pistil interactions, fertilization, and early ovule development following SP and CP by using a paraffin section technique and fluorescence microscopy. The fruit set percentage and seed characteristics also were evaluated among different pollination treatments. The results show that there were no significant differences in pollen tube behavior following SP vs. CP, regardless of the stigmatic or stylar level. Double fertilization was significantly greater following CP (18.09\%) than SP (2.58\%). The significantly lower percentages of ovule penetration and double fertilization in the selfed vs. crossed ovules support a prezygotic LSI mechanism in $C$. mollissima. The fruit set resulting from chase-pollination (CHP; $53.85 \%$ to $63.64 \%$ ) was greater than that resulting from SP $(12.12 \%$ to $14.00 \%)$. In addition, the distribution of aborted seed sizes after SP showed a widely clumped pattern. Abortion occurred at different stages during seed development rather than at aniform stage, which supported the idea that EID was operating in $C$. mollissima. Levels of self-sterility in the chinese chestnut trees ranged from $\mathbf{8 8 . 2} \%$ to $\mathbf{9 0 . 5 \%}$. Thus, partial prezygotic LSI and EID contributed to self-sterility in the $C$. mollissima 'Yanshanzaofeng', with prezygotic LSI rejecting part of the self-pollen in the ovary and EID aborting part of the self-fertilized seeds.
\end{abstract}

Chestnut belongs to the genus Castanea (Fagaceae) and is native to warm, temperate areas in the Northern Hemisphere. Chestnut has played an important role in human nutrition since ancient times, and the chestnut industry is highly developed in Europe, the United States, and Asia (Uylașer et al., 2014). China is one of the most important chestnut-producing countries in the Orient, with an annual production of 1.65 million tonnes, accounting for $82 \%$ of the world's chestnut production (Ji et al., 2018). The demand for nuts is growing in China, and the cultivation area of this species has reached 2 million hectares. It is most widely distributed in Jilin, Hebei, Shandong, Shanxi, Henan, Hubei, and Yunnan provinces (Zou et al., 2013). The nut of chinese chestnut is high in starch content with

Received for publication 31 Dec. 2018. Accepted for publication 18 Mar. 2019. This study was supported by the National Natural Science Foundation of China (grant No. 31500554), Hunan Provincial Natural Science Foundation of China (grant No. 2018JJ3870), and '12th Five year' Science and Technology Support Program of China (grant No. 2013BAD14B04).

${ }^{1}$ Corresponding author. E-mail: zoufeng06@126.com. low fat and thus has high consumer acceptance (Zhang et al., 2015). Furthermore, chestnut production is one of the main income sources in rural regions. The yield of european chestnut (Castanea sativa) in Romania is $7.57 \mathrm{t} \cdot \mathrm{hm}^{-2}$, whereas chinese chestnut is less than $4.55 \mathrm{t} \cdot \mathrm{hm}^{-2}$ in China (Zhu et al., 2014). Low nut yields and increases in alternate bearing are major problems for many chinese chestnut growers. Thus, investigating the factors responsible for low yields and developing culture techniques to enhance yields are important for the development of the chestnut industry in China. In general, understanding the chestnut reproductive process is of basic importance to achieve high-quality chestnut and consistently high production in chestnut orchards. Therefore, studies have been carried out to document the characteristics of sexual reproduction in chestnut, such as their flowering biology (Feng et al., 2011; Guo and Zou, 2014), stigmatic morphology (Shi and Li, 2010), pollination biology (Fan et al., 2014), male and female gamete development (Fan et al., 2015; Zou et al., 2013), fertilization (Masahiro, 2003), and embryological development (Botta et al., 1995; Shi and Stösser, 2005; Zou et al., 2014), which have been proposed 
to be involved in this low fruit set. However, these studies did not explore flower development or the large number of ovules that fail to mature into seeds during fruit development in nature.

Self-sterility is a common reproductive phenomenon in plants. It describes the reduction in seed set following selfing relative to that following outcrossing and is widely distributed among flowering plants (Mahy and Jacquemart, 1999). Selfsterility mainly occurs as a result of self-incompatibility (SI) and EID (Sage et al., 2006). Three types of SI occur in flowering plants: homomorphic sporophytic SI, homomorphic gametophytic SI, and heteromorphic SI (Gibbs, 2014). In sporophytic SI, the germination of incompatible pollen is inhibited at the stigmatic surface (Tangitcharoen and Owens, 1997), but in gametophytic SI, the site of pollen tube inhibition typically is located in the upper third of the style (Peralta et al., 2014). In addition to conventional SI mechanisms, many species demonstrate SI as a result of pollen inhibition in the ovary. This type of SI is called ovarian self-incompatibility or LSI (Thimmaiah et al., 2018). LSI can be prezygotic or postzygotic. If selfed pollen tubes reach the ovary but fertilization does not occur, this type of rejection is consequently prezygotic (Valtueña et al., 2010). Prezygotic SI has been documented in Aconitum kusnezoffii (Hao et al., 2012), Camellia oleifera (Liao et al., 2014), and Narcissus papyraceus (Simón-Porcar et al., 2015). However, if self-fertilization occurs with subsequent postzygotic rejection, this is called postzygotic SI (Valtueña et al., 2010). Postzygotic SI has been demonstrated to occur in Citrus grandis (Chai et al., 2011), Xanthoceras sorbifolium (Zhou and Liu, 2012), and Handroanthus impetiginosus (Júnior, 2017). Many reports have indicated that a critical issue in understanding the basis of self-sterility in plants is determining whether self-rejection is prezygotic or postzygotic (Sage et al., 1999). Furthermore, the timing of the abortion of selfed zygotes in LSI may be prezygotic or postzygotic. Postzygotic SI is more likely to result in developmental failure at a single critical stage (Seavey and Bawa, 1986). However, EID may occur during the whole life cycle of plants, and the consecutive abortion of ovules/seeds may be observed in ovaries/fruit. EID is caused by the expression of recessive alleles at different stages of seed development (Gibbs, 2014). It is difficult to distinguish between postzygotic SI and EID mechanisms in flowering plant species.

Although self-sterility was observed in Castanea species more than half a century ago, the causes of self-sterility are not presently well understood (McKay, 1942). To obtain more detailed information on and assess the timing and mechanism of self-sterility in C. mollissima, we compared pollen germination, pollen tube growth, ovule fertilization, and early embryonic development in terms of morphology and structure following SP vs. CP. Our objectives were to determine whether pollen tubes behave in a similar way in the pistil after SP and CP, whether there are any differences in the rates of ovule penetration and fertilization, and whether the ovules respond in a similar way to SP and CP. In addition, we aimed to address the following questions: are there differences in ovule and embryonic development following CP and SP, and if so, what is the timing of such events? We also investigated the effects of different pollination treatments on the fruit set and fruit and seed characteristics of chinese chestnut. Finally, we evaluated whether pre- or postzygotic LSI and/or EID reduce female reproductive success after SP in C. mollissima.

\section{Materials and Methods}

Plant materials. The 'Yanshanzaofeng' and 'Dabanhong' chinese chestnut were grown in an orchard in Qianxi County, Hebei Province, China, that occurs at $\approx 163 \mathrm{~m}$ above sea level. Qianxi is located at lat. $40^{\circ} 21^{\prime} 57^{\prime \prime} \mathrm{N}$ and long. $118^{\circ} 12^{\prime} 17^{\prime \prime} \mathrm{E}$, with a mean annual precipitation of $744.7 \mathrm{~mm}$ and a mean annual temperature of $10.9^{\circ} \mathrm{C}$ (Zou et al., 2015). One hundred 'Yanshanzaofeng' trees used in the experiments were 12 years old, with an average crown diameter of $3.35 \mathrm{~m}$ and an average height of $3.56 \mathrm{~m}$. The experimental trees were planted at a spacing of $3 \times 4 \mathrm{~m}$ in the orchard. We used the pollen grains of 'Dabanhong' for hand pollination for 'Yanshanzaofeng'. The two varieties/trees are at least $300 \mathrm{~m}$ apart. The management of the chestnut orchard followed standard fertilization practices with supplemental irrigation (Guo and Zou, 2014).

Pollination treatments. The controlled pollination experiments included combinations of SP ('Yanshanzaofeng' $\times$ 'Yanshanzaofeng') and CP ('Yanshanzaofeng' $\times$ 'Dabanhong') and were performed in early June 2012 and 2013. Nonpollination (NP) and CHP treatments also were included in the experiment. Before the blossoming period began, bisexual inflorescences were covered with parchment paper bags $(25 \times$ $30 \mathrm{~cm})$ to prevent fertilization, and the male inflorescences were emasculated. Before the hand-pollination treatment, the pollen viability was evaluated using the fluorescein diacetate test according to Kakade et al. (2017). When the female inflorescences were about to open, SP and CP were performed the following morning from 0800 to $1000 \mathrm{HR}$, and the female inflorescences were quickly rebagged following pollination. In the CHP experiment, we first performed SP treatment and followed with $\mathrm{CP}$ treatment in $24 \mathrm{~h}$ on the same stigma (Hao et al., 2012). In the NP experiment, we only bagged the inflorescences with parchment paper bags before the male inflorescences were emasculated. The bags were removed at the end of June after all the male flowers had withered among the different pollination treatments. Ten pistils were sampled at intervals of $0,3,6,9,12,13,14,15,16,17,18,19,20,21$, $22,23,24,25,27$, and $30 \mathrm{~d}$ from the trees in each treatment after pollination for the observation of pollen tube growth into the pistils. All samples were fixed in a formalin: glacial acetic acid: $70 \%$ ethyl alcohol $(1: 1: 18 \mathrm{v} / \mathrm{v})$ solution and then stored at $4{ }^{\circ} \mathrm{C}$ (Zou et al., 2014). For each pollination combination, 500 flowers were pollinated and used for fluorescence analysis and sectioning. Furthermore, $\approx 500$ pollinated flowers from 12 chestnut trees (three trees per treatment) were used to investigate fruit set after SP, CP, CHP, and NP.

Pollen tube behavior in the STYle AND OVARy AFTer SP AND CP. For each treatment, the pistils at 0 to $25 \mathrm{~d}$ after SP and $\mathrm{CP}$ were decolorized overnight in a diluted $(0.01 \%)$ solution of sodium hypochlorite at room temperature. After rinsing three times in water, they were hydrated and softened in $1 \mathrm{M} \mathrm{NaOH}$ for 2 to $3 \mathrm{~h}$ at $45^{\circ} \mathrm{C}$ (Sogo and Tobe, 2005). The samples were

Table 1. Pollen viability of chinese chestnut for hand-pollination.

\begin{tabular}{lc}
\hline Cultivar & Viable pollen rate [mean \pm SD (\%)] \\
\hline Yanshanzaofeng & $86.9 \pm 1.5 \mathrm{a}^{\mathrm{z}}$ \\
Dabanhong & $81.2 \pm 2.5 \mathrm{a}$
\end{tabular}

${ }^{\mathrm{z}}$ Same letters within the same column represent no significant differences at the $5 \%$ level as determined by Duncan's multiple range test. 
placed on a slide, stained with $0.05 \%$ aniline blue in $0.15 \mathrm{M} \mathrm{K}_{2} \mathrm{HPO}_{4}$ for 4 to $12 \mathrm{~h}$, and covered with a cover glass (Gao et al., 2015). Pollen grain germination and pollen tube growth were observed and photographs were taken using a fluorescence microscope (BX-51; Olympus, Tokyo, Japan). We described pollen-tube growth by recording the length of the longest tube as extending one-quarter, one-half, threequarters, or the entire length of the carpel according to Kawagoe and Suzuki (2005). The average value for each collection day for each sample was used in the analysis.

The pollen tubes that penetrated into the ovules in both the SP and $\mathrm{CP}$ treatments were examined from 18 to $25 \mathrm{~d}$ after pollination (DAP) to detect callose. The sections were stained with $0.05 \%$ decolorized aniline blue in $0.15 \mathrm{M} \mathrm{K}_{3} \mathrm{PO}_{4}$ for 4 to $12 \mathrm{~h}$ (Zou et al., 2013). Pollen tube growth in the ovules was photographed under a fluorescence microscope (BX-51) and measured with ImageJ (National Institutes of Health, Bethesda, MD).

Double FERTILIzATION AND EARLY EMBRYO DEVELOPMENT FOLLOWING SP AND CP. Between 18 and $30 \mathrm{~d}$ after SP and $\mathrm{CP}$, ovaries were dehydrated through an ethyl-alcohol series, embedded in paraffin, and sectioned at a thickness of $10 \mu \mathrm{m}$ with a microtome (RM2265; Leica, Wetzlar, Germany). The sections were stained with hematoxylin or Safranin-O/Fast Green to detect double fertilization, embryo sacs, and ovule development (Zou et al., 2014). Serial sections were scored for double fertilization as indicated by Sage and Sampson (2003). We also examined the area of embryo sacs in self-fertilized, crossfertilized, and nonfertilized ovules with ImageJ software to identify quantitative differences in area 21,23 , and 25 DAP. The sections were observed and photographed using a microscope (BX-51) under a bright field.

FRUIT SET AND SEED AND FRUIT CHARACTERISTICS. We evaluated the fruit set and the fruit and seed characteristics among the different pollination treatments when chestnut were harvested in early September. The fruit set was calculated according to Liu et al. (2012). Fruit and seed characteristics, including the mean single fruit weight, seed length, and width, also were examined (Pérez and López, 2009). We calculated the $\mathrm{CV}$ of the aborted seed length separately for the SP and CP treatments. The number of seeds in each cupula was counted to provide an estimate of the degree of self-sterility in each experimental tree. Self-sterility (percent) was determined according to Pound et al. (2002).

STATISTICAL ANALYSIS. The SPSS statistical package (version 19.0; IBM Corp, Armonk, NY) and Microsoft Excel 2010 software (Microsoft, Redmond, WA) were used for the majority of the statistical analyses. Significant differences among means were assessed using Duncan's multiple comparison test at $P \leq$
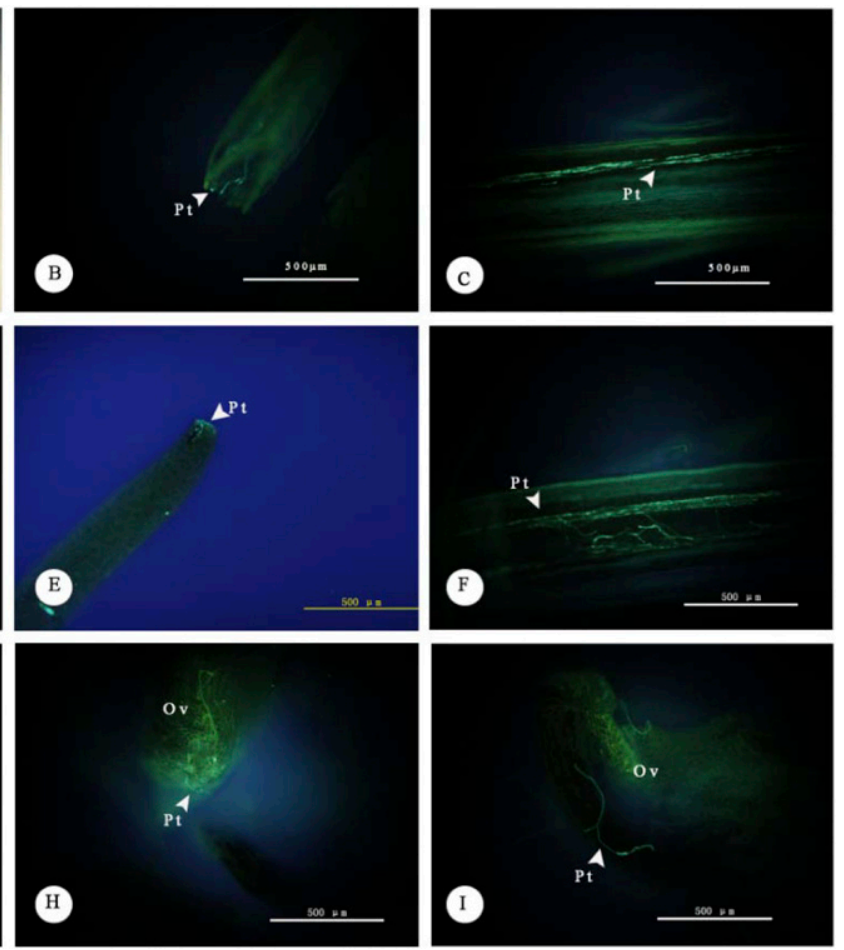

ig. 1. Pollen germination, pollen tube growth, and ovule penetration after self-pollination (SP) and crossat had begun to germinate on the stigma 3 after $C P$. $(\mathbf{F})$ pollen tubes that grew in the middle of the grain the ovule $20 \mathrm{~d}$ after $\mathrm{SP} ;(\mathbf{I})$ a pollen tube that had penetrated the ovule $18 \mathrm{~d}$ after $\mathrm{CP}$. Or = ovary; $\mathrm{Ov}=$ ovule; $\mathrm{Pt}=$ pollen tube; $\mathrm{Sg}=$ stigma; $\mathrm{St}=$ style.

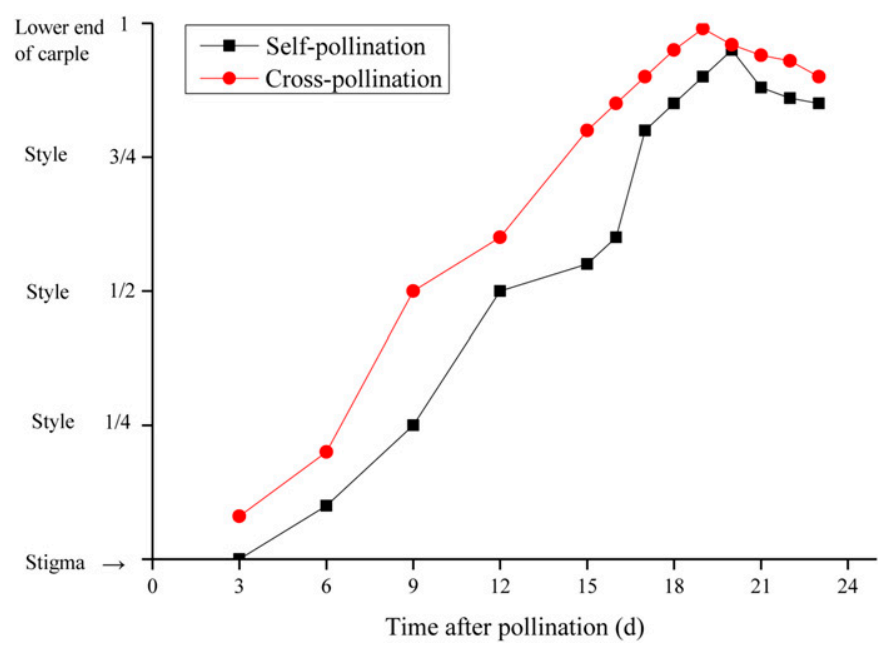

Fig. 2. Growth of selfed and crossed pollen tubes in carpels of chinese chestnut, shown by whether the most elongated pollen tube reached one-quarter, onehalf, or three-quarters of the way down to the carpels or the lower end of the carpel.

0.05 . We also performed $\chi^{2}$ tests to investigate whether there were significant differences in the proportion of fertilized ovules and the number of nuts in a single cupula among the different treatments (Streher et al. 2018). Statistical data with a value of 0 were read as N/A, and they were treated as missing 
values. Figures were generated using the Origin 8.5 software (Origin Laboratory, Northampton, MA).

\section{Results}

Pollen viability. As shown in Table 1, the percentage of viable pollen did not significantly differ between the 'Yanshanzaofeng' $(86.9 \% \pm 1.5 \%)$ and 'Dabanhong' $(81.2 \% \pm 2.5 \%)$. This result indicates that the male gamete of the 'Yanshanzaofeng' was normal.

Pollen Germination AND POLLEN-TUBE GROWTH IN THE PISTIL of C. mollissima fOllowing CP AND SP. No morphologic or structural differences in terms of pollen germination or pollen tube growth in the style were observed following SP and CP (Fig. 1B-G). The female flower of the 'Yanshanzaofeng' has six to nine stigmas and styles and one ovary (Fig. 1A). Three days after SP, we observed that few pollen grains germinated on the stigma. Six days after SP, a small number of pollen tubes germinated on the stigma (Fig. 1B), whereas the pollen tubes germinated $3 \mathrm{~d}$ after $\mathrm{CP}$ under the fluorescence microscope (Fig. 1E). Twelve days after SP, the pollen tubes had extended to $\approx 1 / 2$ of the style length (Fig. 1C), whereas $9 \mathrm{~d}$ was required to grow to this length following CP (Fig. $1 F)$. It took $\approx 17 \mathrm{~d}$ for the normal selfed tubes to grow through the style (Fig. 1D) but only $15 \mathrm{~d}$ for the crossed tubes (Fig. 1G).

The first pollen tubes penetrated the ovule 20 and $18 \mathrm{~d}$ after SP and $\mathrm{CP}$, respectively (Fig. 1H and I). The pollen grains germinated normally and were able to grow through the style and even penetrate the ovule, regardless of whether they were produced as a result of SP or CP. In addition, our evaluation of pollentube growth indicated that the pollen tubes grew into the carpels at different time points after SP and CP (Fig. 2). However, differences were observed in the penetration of ovules by pollen tubes following SP compared with that in CP. A large proportion of abnormal pollen tubes were observed in the ovary after SP (Fig. 3). In the present study, distorted pollen tubes, including irregular tubes (Fig. 3A), degraded pollen tubes (Fig. $3 \mathrm{~B}$ and $\mathrm{C}$ ), reversed tubes (Fig. 3D and E), and tubes with swollen tips, were observed (Fig. 3F).

Fertilization AND EARLy OVULE DEVElopment in $\boldsymbol{C}$. mollissima following CP AND SP. Double fertilization was demonstrated based on the fusion between sperm and egg cells or between a polar nucleus and sperm cells, as indicated by the presence of proembryos and free endosperm nuclei after both SP and CP (Fig. 4). Most CP ovules were fertilized and

developed into a mature embryo sac. When the pollen tube penetrated the micropyle, one male nucleus moved toward the egg cell and fused with it $18 \mathrm{~d}$ after CP (Fig. 4G). A proembryo was observed in the embryo sac after $21 \mathrm{~d}$ (Fig. $4 \mathrm{H})$ and formed a free nuclear layer encircling the embryo sac wall $22 \mathrm{~d}$ after $\mathrm{CP}$ (Fig. 4I). A larger number of free endosperm nuclei appeared in the embryo sac wall $23 \mathrm{~d}$ after CP (Fig. 4J). The proembryo continued to develop into a globular embryo $27 \mathrm{~d}$ after CP (Fig. 4L). However, the SP ovules could also be fertilized (Fig. 4AF) and developed into globular embryos (Fig. 4K). There were no structural differences between the normal selfed and crossed embryos based on the anatomical observations (Fig. 4), but differences were observed in the frequency of double fertilization and ovule sterility (Table 2). The greatest percentage of double fertilization observed after SP $(2.58 \%)$ was significantly lower than that after CP $(18.09 \%)$ on the same day after pollination $\left[\chi_{(0.05)}^{2}=32.11, P<0.001\right]$, which corresponded to the differences in the penetration of SP and CP ovaries. SP resulted in a lower occurrence of double fertilization at all times 

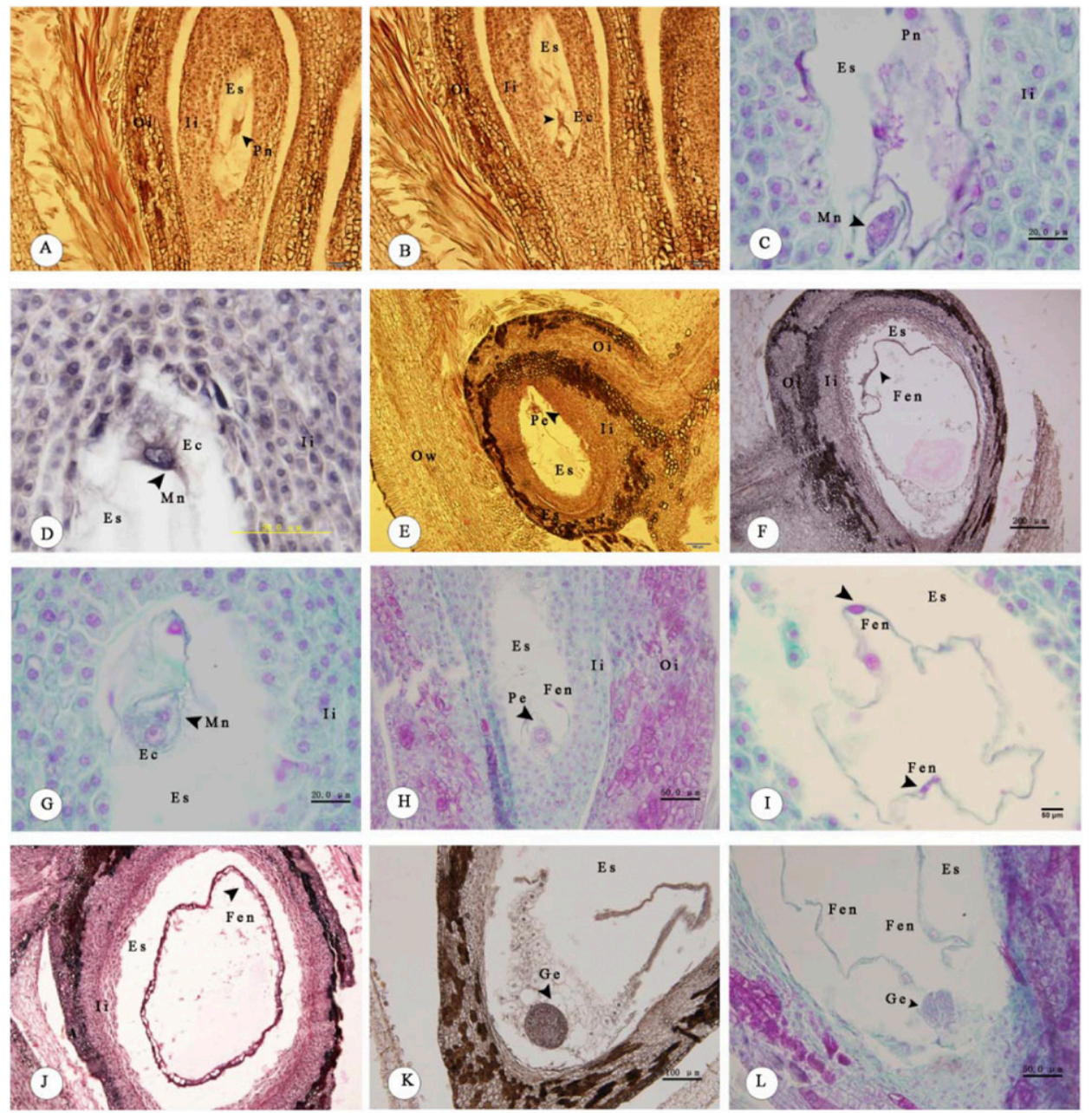

Fig. 4. Normal double fertilization and early embryonic development after self-pollination (SP) and crosspollination (CP) in chinese chestnut: (A) longitudinal section showing the inner and outer integuments and two polar nuclei located in the embryo sac $18 \mathrm{~d}$ after SP; (B) longitudinal section showing the inner and outer integuments and egg cells located in the embryo sac $18 \mathrm{~d}$ after SP; (C) longitudinal section showing the inner integument, polar nucleus, and two male nuclei located at the micropylar end $19 \mathrm{~d}$ after SP; (D) longitudinal section showing the inner integument and a male nucleus beginning to fuse with an egg cell in the embryo sac 20 $\mathrm{d}$ after SP; (E) longitudinal section showing the ovary wall, the inner and outer integuments, and a proembryo in the embryo sac $23 \mathrm{~d}$ after SP; (F) longitudinal section showing the inner and outer integuments and a large number of free endosperm nuclei forming a circular free nuclear layer along the embryo sac wall $25 \mathrm{~d}$ after SP; (G) transverse section showing the inner integument and a male nucleus beginning to fuse with an egg cell in the embryo sac $18 \mathrm{~d}$ after CP; (H) longitudinal section showing the inner and outer integuments, free endosperm nuclei and a proembryo in the embryo sac $21 \mathrm{~d}$ after CP; (I) longitudinal section showing free endosperm nuclei in the embryo sac $22 \mathrm{~d}$ after $\mathrm{CP} ;(\mathbf{J})$ longitudinal section showing the inner and outer integuments and a large number of free endosperm nuclei forming a circular free nuclear layer along the embryo sac wall $23 \mathrm{~d}$ after $\mathrm{CP}$; (K) longitudinal section showing a globular embryo $30 \mathrm{~d}$ after SP; (L) longitudinal section showing free endosperm nuclei and a globular embryo $27 \mathrm{~d}$ after $\mathrm{CP} . \mathrm{Ec}=$ egg cell; Es = embryo sac; Fen = free endosperm nuclei; $\mathrm{Ge}=$ globular embryo; $\mathrm{Ii}=$ inner integument; $\mathrm{Mn}=$ male nucleus; $\mathrm{Ow}=$ ovary wall; $\mathrm{Oi}=$ outer integument; $\mathrm{Pe}=$ proembryo; $\mathrm{Pn}=$ polar nuclei

compared with $\mathrm{CP}$, suggesting that certain fertilization barriers existed.

To examine the irregular anatropous ovules in C. mollissima, the mean embryo sac area was measured at various stages following SP and CP (Table 3). There were no significant differences in the mean area between the self- and cross-fertilized ovules, but significant differences were observed in the nonfertilized ovules. Under the same pollination conditions, we observed increases in both selfed and crossed seeds in both the SP and CP treatments, which indicates that the ovule volume rapidly expanded following fertilization. However, the embryo sac area in the nonfertilized ovules decreased $25 \mathrm{~d}$ after harvesting, suggesting that the ovules were aborted.

A small number of SP vs. CP ovules developed normally into mature seeds through double fertilization. Aborted ovules were mostly observed during seed formation. The occurrence of abortion was judged based on structural characteristics, with a strongly stained embryo sac (Fig. 5). Figure 5 shows ovules with shriveling embryo sacs but normal integument development (Fig. 5A and B), embryo sacs with cavities (Fig. 5C), degenerated postaments (Fig. 5D) and shrinking ovules with completely dead tissue (Fig. 5E and F) at different stages following SP.

FruIT SET AND FRUIT AND SEED CHARACTERISTICS OF C. MOLLISSIMA AMONG THE DIFFERENT POLLINATION TREATMENTS. There were significant differences in fruit set and the mean number of seeds per flower among the different pollination treatments. SP of $C$. mollissima resulted in a lower rate of fruit set than that obtained by CP (Table 4). SP resulted in a very low fruit set of $12.12 \%$ to $14.00 \%$, while the CP fruit set was $77.14 \%$ to $79.41 \%$, and the CHP fruit set was $53.85 \%$ to $63.64 \%$. Self-sterility levels for the three maternal parent trees ranged from $88.2 \%$ to $90.5 \%$ (Table 4 ).

There were significant differences in the number of nuts in a single cupula among the different pollination treatments $\left[\chi_{(0.05)}^{2}=\right.$ $13.54, P=0.019 ; \chi^{2}(0.05)=3.38$, $P=0.642 ; \chi_{(0.05)}^{2}=35.34, P<$ 0.001 , respectively (Table 5)]. In this investigation, there was a high number of cupulae with only one or two nuts in the SP treatment. Only $12.5 \%$ to $17.6 \%$ of the cupulae contained three nuts after SP, whereas $37.5 \%$ to $45.0 \%$ of the cupulae contained three nuts after CP. All cupulae were empty in the NP treatment (Table 5, Fig. 7C), indicating that no apomixis occurred in the 'Yanshanzaofeng'.

The weight of an individual nut was dependent on the number of nuts in a cupula. Greater numbers of nuts resulted in lower nut weights. The mean cupula weights in the four pollination treatments of SP, CP, CHP, and NP were (mean \pm SD) $23.94 \pm 6.38,37.65 \pm 6.32,35.42 \pm 5.24$, and $14.60 \pm 2.98$ g, respectively (Table 6, Fig. 7), and these weights showed significant differences. In contrast, no significant differences were observed in terms of the mature seed length or seed width 
Table 2. Anatomical features of fertilized ovules of chinese chestnut following self- and cross-pollination at 21, 23, and $25 \mathrm{~d}$ after pollination (DAP).

\begin{tabular}{|c|c|c|c|c|c|c|c|c|}
\hline DAP & $\begin{array}{l}\text { Pollination } \\
\text { treatment }^{z}\end{array}$ & $\begin{array}{c}\text { Samples } \\
\text { observed (no.) }\end{array}$ & $\begin{array}{c}\text { Double } \\
\text { fertilization }(\%)^{\mathrm{y}}\end{array}$ & & $\begin{array}{c}\text { Proembryos } \\
(\%)^{\mathrm{y}}\end{array}$ & & $\begin{array}{c}\text { Endosperm } \\
(\%)^{\mathrm{y}}\end{array}$ & \\
\hline \multirow[t]{2}{*}{21} & SP & 151 & 2.21 & \multirow{6}{*}{$\begin{array}{c}\chi_{(0.05)}^{2}=32.11 \\
P<0.001\end{array}$} & 0.98 & \multirow{6}{*}{$\begin{array}{c}\chi_{(0.05)}^{2}=14.00 \\
P=0.016\end{array}$} & 1.04 & \multirow{6}{*}{$\begin{array}{c}\chi_{(0.05)}^{2}=15.86 \\
P=0.007\end{array}$} \\
\hline & $\mathrm{CP}$ & 148 & 4.53 & & 1.59 & & 2.79 & \\
\hline \multirow[t]{2}{*}{23} & SP & 155 & 2.58 & & 0.77 & & 1.15 & \\
\hline & $\mathrm{CP}$ & 152 & 18.09 & & 8.25 & & 9.46 & \\
\hline \multirow[t]{2}{*}{25} & SP & 158 & 0.94 & & 0.85 & & 0.91 & \\
\hline & $\mathrm{CP}$ & 153 & 8.78 & & 3.26 & & 5.79 & \\
\hline
\end{tabular}

${ }^{\mathrm{z}} \mathrm{SP}=$ self-pollination, $\mathrm{CP}=$ cross-pollination.

${ }^{\mathrm{y}}$ Significant difference in the double fertilization, proembryo, and endosperm between SP and CP treatments by $\chi^{2}$ test.

Table 3. The area of embryo sacs in self-fertilized, cross-fertilized, and nonfertilized ovules of chinese chestnut at 21,23 , and $25 \mathrm{~d}$ after pollination (DAP).

\begin{tabular}{lcrc}
\hline & \multicolumn{3}{c}{ Embryo sac area $\left[\mu \mathrm{m}^{2}(\mathrm{mean} \pm \mathrm{SD})\right]^{\mathrm{z}}$} \\
\cline { 2 - 4 } DAP & \multicolumn{4}{c}{ SF } & CF & $\mathrm{NF}$ \\
\hline 21 & $2,579.70 \pm 205.31 \mathrm{c}^{\mathrm{y}}$ & $3,529.35 \pm 158.66 \mathrm{c}$ & $1,997.85 \pm 249.45 \mathrm{a}$ \\
23 & $4,403.66 \pm 245.11 \mathrm{~b}$ & $5,404.56 \pm 236.87 \mathrm{~b}$ & $938.79 \pm 103.05 \mathrm{~b}$ \\
25 & $15,020.00 \pm 757.71 \mathrm{a}$ & $16,509.46 \pm 401.59 \mathrm{a}$ & $296.36 \pm 91.07 \mathrm{c}$ \\
\hline
\end{tabular}

${ }^{\mathrm{z}} \mathrm{SF}=$ self-fertilized, $\mathrm{CF}=$ cross-fertilized, $\mathrm{NF}=$ nonfertilized.

${ }^{\mathrm{y}}$ Different letters within the same column represent significant differences at the $5 \%$ level as determined by Duncan's multiple range test.

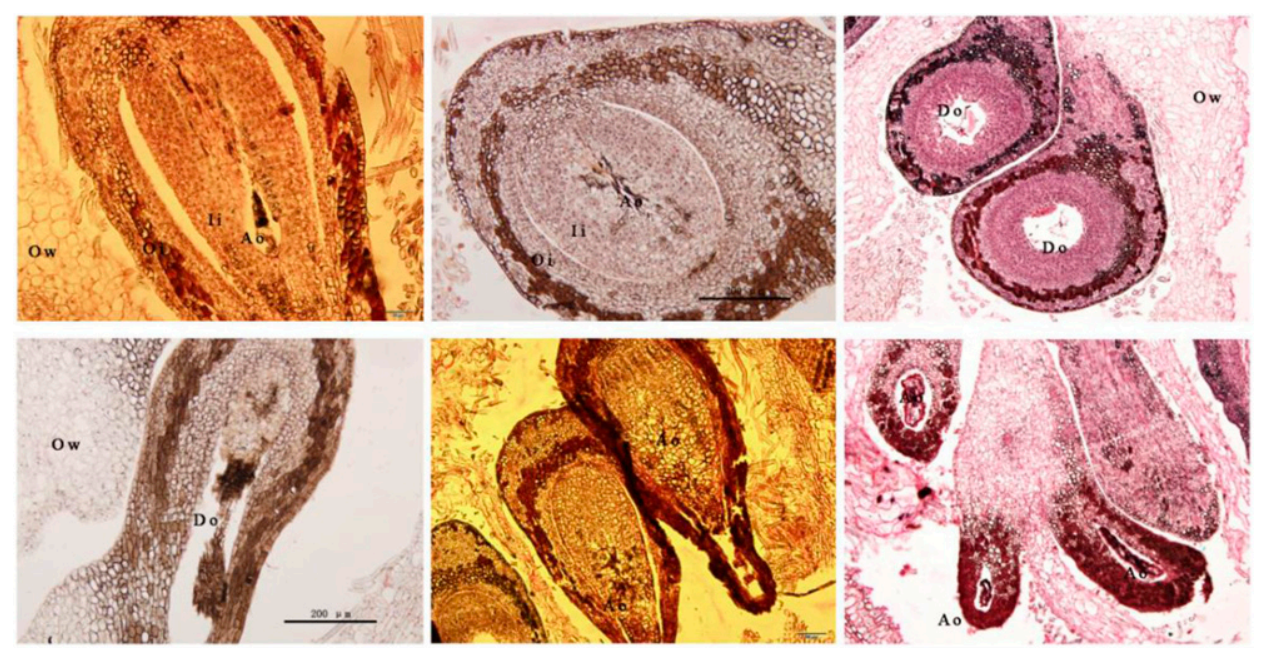

Fig. 5. Degenerating and aborted ovules in self-pollinated (SP) ovaries at various stages in chinese chestnut: (A) longitudinal sections showing that the aborted ovules were darkly stained $20 \mathrm{~d}$ after SP; (B) longitudinal section showing aborted ovules with shrunken embryo sacs $21 \mathrm{~d}$ after SP; (C) longitudinal section showing degenerated ovules with cavities in the embryo sacs $22 \mathrm{~d}$ after SP; (D) longitudinal section showing aborted ovules with degenerated postament $23 \mathrm{~d}$ after SP; $(\mathbf{E}-\mathbf{F})$ longitudinal section showing aborted ovules $25 \mathrm{~d}$ after SP. Ao $=$ aborted ovule; $\mathrm{Do}=$ degenerate ovule; $\mathrm{Ii}=$ inner integument; $\mathrm{Ow}=$ ovary wall; $\mathrm{Oi}=$ outer integument.

after SP and $\mathrm{CP}$ in C. mollissima (Table 6). However, the $\mathrm{Cv}$ of the length of aborted SP seeds $(\mathrm{CV}=74.98 \%)$ was greater than that of aborted CP seeds $(\mathrm{CV}=29.99 \%)$ (Fig. 6).

\section{Discussion}

The major finding of this study was that self-sterility in $C$. mollissima 'Yanshanzaofeng' resulted in reduced fruit set following SP compared with CP and principally occurred as a result of two mechanisms: LSI and EID. Consequently, the possible causes of self-sterility in C. mollissima are discussed in detail to follow through comparison with other species having similar characteristics.

L A T E - A C T I N G S E L F INCOMPATIBILITY. Self-sterility in flowering plant species is commonly the result of genetic SI, which can act before fertilization (Hokanson and Hancock, 2000). However, in some plant species, the mechanisms of SI expression may occur after fertilization, which is indicative of LSI (Nuortila et al., 2006). LSI, including both prezygotic and postzygotic forms, is a type of SI in which pollen tubes that form following SP successfully grow through the style to the ovules, but the flowers fail to produce fruit and seeds (Vaughton et al., 2010). Histologic characterization of pollen tube growth, penetration of the ovule, fertilization, and embryo development has facilitated the identification of various types of interactions between self-pollen tubes and the style/ovules in taxa showing LSI.

Based on histologic observations of the pistil structure and the detailed analysis of the percentages of pollen tubes at different locations in the pistils following SP in comparison with $\mathrm{CP}$, there were no significant differences in the morphologic structure or percentage of pollen grains that had germinated on the stigma, pollen tubes that grew in the middle of the style, or pollen tubes that had grown through the style (Figs. 1 and 2). Similar observations have been documented for other species, including Ipomopsis aggregata (Sage et al., 2006), Eucalyptus urophylla (Horsley and Johnson, 2007), and C. oleifera (Liao et al., 2014). In these species, SP and $\mathrm{CP}$ tubes were found to have a similar appearance through the stigma and style, but the SP tubes were inhibited in the ovary 19 DAP. In chinese chestnut, the majority of the abnormal pollen tubes were observed in the ovary after SP (Fig. 3), suggesting that certain self-fertilization barriers exist. This findings of abnormal pollen tubes are similar to those 
Table 4. Number of pollinated flowers and fruit set and mean number of seeds per flower following self-pollination, cross-pollination, chase-pollination, and nonpollination treatments of chinese chestnut and level of self-sterility (SS).

\begin{tabular}{|c|c|c|c|c|c|c|}
\hline No. & $\begin{array}{l}\text { Pollination } \\
\text { treatment }^{z}\end{array}$ & $\begin{array}{l}\text { Flowers } \\
\text { (no.) }\end{array}$ & $\begin{array}{c}\text { Fruit } \\
\text { set }(\%)\end{array}$ & $\begin{array}{l}\text { Mean seeds } \\
\text { (no./flower) }\end{array}$ & $P^{\mathrm{y}}$ & SS $(\%)$ \\
\hline \multirow[t]{4}{*}{1} & SP & 166 & 12.12 & 0.15 & $<0.001$ & 90.5 \\
\hline & $\mathrm{CP}$ & 162 & 79.03 & 1.58 & & \\
\hline & CHP & 178 & 53.85 & 0.92 & & \\
\hline & NP & 163 & $\mathrm{~N} / \mathrm{A}^{\mathrm{x}}$ & N/A & & \\
\hline \multirow[t]{4}{*}{2} & SP & 150 & 14.00 & 0.18 & & 88.2 \\
\hline & $\mathrm{CP}$ & 170 & 77.14 & 1.53 & & \\
\hline & CHP & 160 & 58.33 & 1.01 & & \\
\hline & NP & 165 & $\mathrm{~N} / \mathrm{A}$ & N/A & & \\
\hline \multirow[t]{4}{*}{3} & SP & 180 & 13.75 & 0.19 & & 88.3 \\
\hline & $\mathrm{CP}$ & 168 & 79.41 & 1.62 & & \\
\hline & CHP & 155 & 63.64 & 1.14 & & \\
\hline & NP & 172 & N/A & N/A & & \\
\hline
\end{tabular}

${ }^{\mathrm{z}} \mathrm{SP}=$ self-pollination, $\mathrm{CP}=$ cross-pollination, $\mathrm{CHP}=$ chase-pollination, $\mathrm{NP}=$ nonpollination. ${ }^{\mathrm{y}}$ Probability values represent comparisons between the mean number of SP, CP, CHP, and NP seeds per capsule.

${ }^{\mathrm{x}} \mathrm{N} / \mathrm{A}=0$.

Table 5. Number of nuts in a single cupula at harvest after the self-pollination, cross-pollination, and nonpollination treatments of chinese chestnut.

\begin{tabular}{|c|c|c|c|c|c|c|c|}
\hline No. & $\begin{array}{l}\text { Pollination } \\
\text { treatment }^{z}\end{array}$ & $\begin{array}{c}\text { One } \\
\text { nut }(\%)^{y}\end{array}$ & & $\begin{array}{c}\text { Two } \\
\text { nuts }(\%)\end{array}$ & & $\begin{array}{c}\text { Three } \\
\text { nuts (\%) }\end{array}$ & \\
\hline \multirow[t]{3}{*}{1} & SP & 47.1 & \multirow{9}{*}{$\begin{array}{c}\chi_{(0.05)}^{2}=13.54 \\
P=0.019\end{array}$} & 35.3 & $\chi_{(0.05)}^{2}=3.38$, & 17.6 & $\chi_{(0.05)}^{2}=35.34$, \\
\hline & $\mathrm{CP}$ & 29.2 & & 33.3 & $P=0.642$ & 37.5 & $P<0.001$ \\
\hline & NP & $\mathrm{N} / \mathrm{A}^{\mathrm{x}}$ & & N/A & & $\mathrm{N} / \mathrm{A}$ & \\
\hline \multirow[t]{3}{*}{2} & SP & 50.0 & & 37.5 & & 12.5 & \\
\hline & $\mathrm{CP}$ & 30.0 & & 25.0 & & 45.0 & \\
\hline & NP & $\mathrm{N} / \mathrm{A}$ & & $\mathrm{N} / \mathrm{A}$ & & N/A & \\
\hline \multirow[t]{3}{*}{3} & SP & 48.2 & & 36.1 & & 15.7 & \\
\hline & $\mathrm{CP}$ & 29.6 & & 30.3 & & 40.1 & \\
\hline & NP & $\mathrm{N} / \mathrm{A}$ & & N/A & & N/A & \\
\hline
\end{tabular}

${ }^{\mathrm{z}} \mathrm{SP}=$ self-pollination, $\mathrm{CP}=$ cross-pollination, $\mathrm{NP}=$ nonpollination.

${ }^{\mathrm{y}}$ Significant difference in the number of nuts in one cupula between SP, CP, and NP treatments were used by the $\chi^{2}$ test.

${ }^{\mathrm{x}} \mathrm{N} / \mathrm{A}=0$.

Table 6. The cupula weight and mature seed characteristic values following self-pollination, crosspollination, chase-pollination, and nonpollination treatments of chinese chestnut.

\begin{tabular}{lccc}
\hline & Cupula wt $(\mathrm{g})$ & Seed length $(\mathrm{mm})$ & Seed width $(\mathrm{mm})$ \\
\cline { 2 - 4 } Pollination treatment $^{\mathrm{z}}$ & $23.94 \pm 6.38 \mathrm{~b}^{\mathrm{y}}$ & $22.42 \pm 1.11 \mathrm{a}$ & $24.65 \pm 2.07 \mathrm{a}$ \\
SP & $37.65 \pm 6.32 \mathrm{a}$ & $20.41 \pm 1.57 \mathrm{a}$ & $25.08 \pm 1.64 \mathrm{a}$ \\
CP & $35.42 \pm 5.24 \mathrm{a}$ & $19.38 \pm 1.17 \mathrm{~b}$ & $24.33 \pm 1.16 \mathrm{a}$ \\
CHP & $14.60 \pm 2.98 \mathrm{c}$ & N/A $^{\mathrm{x}}$ & N/A \\
NP &
\end{tabular}

${ }^{\mathrm{z}} \mathrm{SP}=$ self-pollination, $\mathrm{CP}=$ cross-pollination, $\mathrm{CHP}=$ chase-pollination, $\mathrm{NP}=$ nonpollination .

${ }^{\mathrm{y}}$ Different letters within the same column represent significant differences at the $5 \%$ level based on Duncan's multiple range test, whereas the same letter represents no significant differences.

${ }^{\mathrm{x}} \mathrm{N} / \mathrm{A}=0$.

described in C. oleifera (Liao et al., 2014) and N. papyraceus (Simón-porcar et al., 2015). In addition, double fertilization was observed in both SP and CP ovules, with no structural or histologic differences (Fig. 4). However, the frequency after SP $(2.58 \%)$ was much lower than that after CP $(18.09 \%)$ (Table 2), which could be attributed to reduced ovule penetration in selfed ovules. This similar results has been previously described in other species by Tomás et al. (1999) and Liao et al. (2014). In the studied species, we have demonstrated that the recognition of self-pollen in C. mollissima flowers is prezygotic and is associated with the abnormal development of the embryo sac in ovules. Abnormal ovules were identified based on structural characteristics, having a strongly stained embryo sac $20 \mathrm{~d}$ after SP (Fig. 5). These abnormal ovules affect double fertilization, and the embryo sac area in nonfertilized ovules decreased (Table 3). SP in C. mollissima leads to the occurrence of aborted ovules at an early stage of development (Fig. 5, Table 3 ), suggesting that self-sterility occurs in this species. The levels of self-sterility in the chinese chestnut trees ranged from $88.2 \%$ to $90.5 \%$. These data suggest that self-sterility in 'Yanshanzaofeng' occurs as a result of a prezygotic SI-based mechanism.

Our results also confirmed that $C$. mollissima is a prezygotic plant that exhibits LSI and that there was fruit set under CHP but not under SP (Table 4). If a postzygotic mechanism was wholly responsible for the reduction in female fitness with no associated prezygotic LSI, all of the ovules in the CHP treatments would be fertilized by the first-arriving self-pollen grains; hence, the fruit set would be similar to that after SP (Hao et al., 2012). However, as observed in our study, the fruit set resulting from CHP $(53.85 \%$ to $63.64 \%)$ was greater than that resulting from SP $(12.12 \%$ to $14.00 \%$ ) when the cross-pollen was applied $1 \mathrm{~d}$ after self-pollen. It can be assumed that a proportion of the cross-pollen tubes reached the ovary within a period of time that permitted them to penetrate the ovules to prevent fruit abscission and allow fruit development. This result supports the hypothesis that prezygotic LSI occurs in C. mollissima. However, if the prezygotic LSI prevented all of the self-pollen from fertilizing ovules, the first-arriving self-pollen grains would not be able to fertilize any ovules in the CHP treatment, and the ovules would then be available to the ensuing cross-pollen grains, leading to a fruit set similar to that in the $\mathrm{CP}$ treatment, 
as evidenced by Hao et al. (2012). In our case, we found that the fruit set in the CHP treatment was lower than that in the CP treatment (77.14\% to $79.41 \%)$, indicating that the first-arriving self-pollen grains fertilized some but not all of the ovules. In the CHP the late-arriving cross-pollen significantly increased the seed set, thus it seems that most of ovules were available for

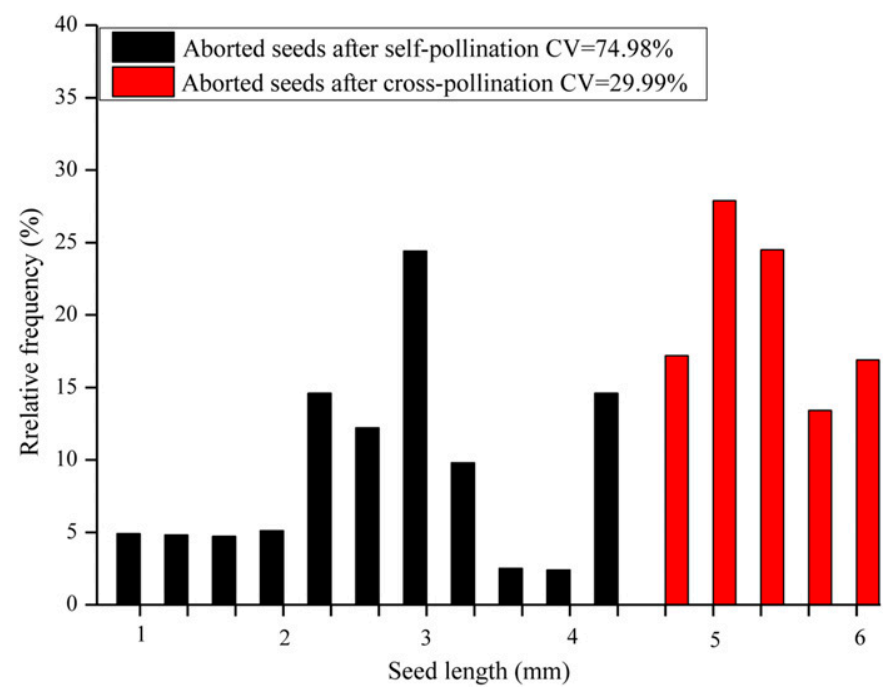

Fig. 6. Distributions of aborted seed length and the $\mathrm{CV}$ for chinese chestnut in the self- and cross-pollination treatments.
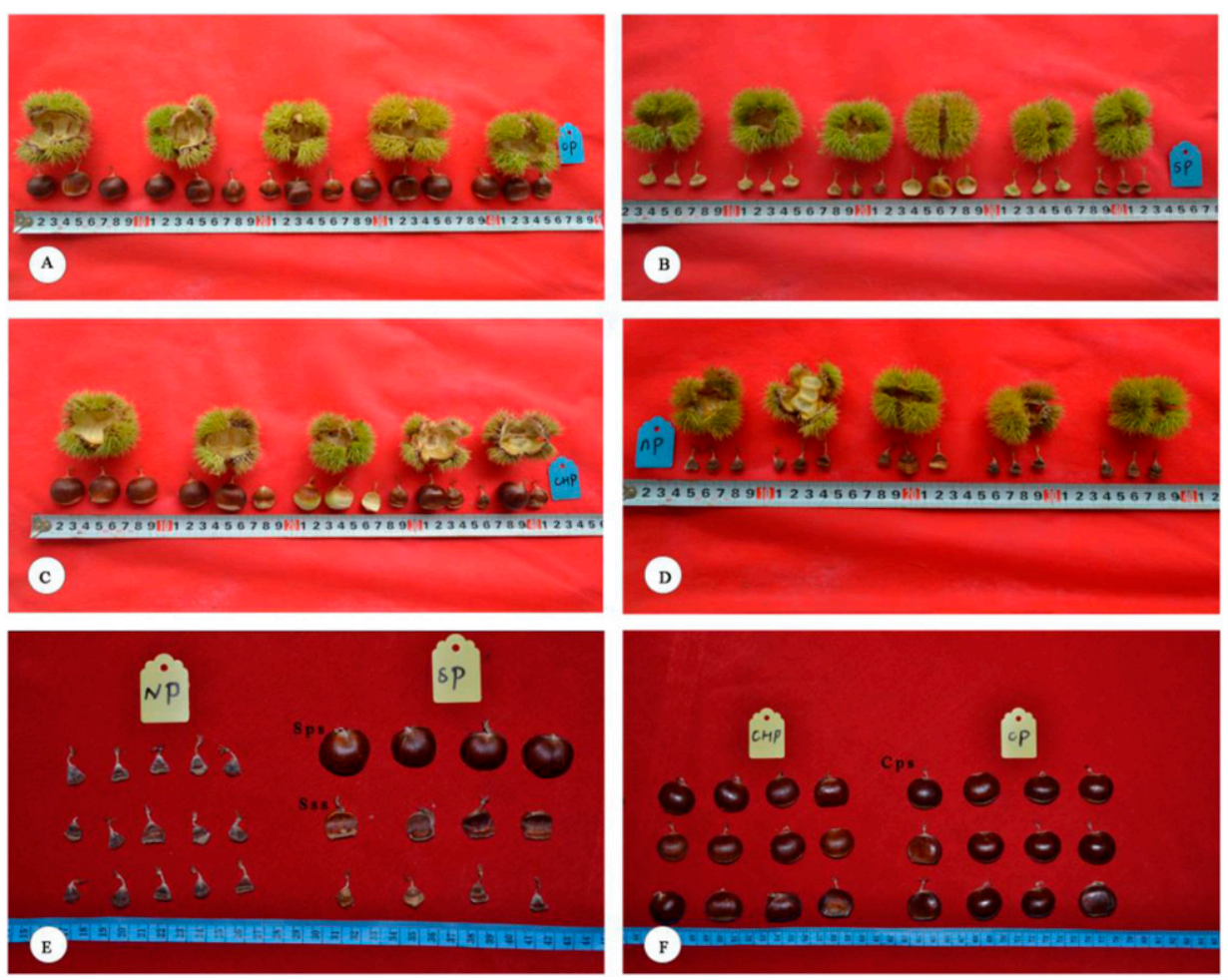

Fig. 7. Mature fruit, mature seeds, and aborted seeds after self-pollination (SP), cross-pollination (CP), chasepollination (CHP), and nonpollination (NP) treatments in chinese chestnut: (A) mature cupula and seed characteristics following CP; (B) mature cupula and seed characteristics following SP; (C) mature cupula and aborted seed characteristics following CHP; (D) mature cupula and aborted seed characteristics following NP; (E) comparison of seed characteristics between the NP and SP treatments; (F) mature seed characteristics following CP and CHP. Cps = CP seed; Sps = SP seed; Sss = self-sterile seed. fertilization by cross-pollen in the chase-pollinated fruit. One possible explanation is that although some self-pollen tubes could grow into ovaries after hand-pollination, not all of the pollen tubes immediately released sperms and garnered the ovules; as a consequence, a higher-than-expected proportion of the ovules were still available when the cross-pollen tubes arrived $1 \mathrm{~d}$ later. Therefore, C. mollissima presents partial prezygotic LSI, with the rejection of some of the self-pollen in exhibiting LSI in the Bombacaceae (Gibbs et al., 2004) and Ranunculaceae families (Hao et al., 2012). In addition, selfpollen can disable ovules by affecting the development of the eryo sac rather than fertilizing the ovules. Thus, the CHP experiment may underestimate the importance of prezygotic SI in C. mollissima.

Furthermore, the fruit set after SP was lower than that after in chinese chestnut. Fan and Luo (1993) reported that the fruit set of SP varied from $2.70 \%$ to $9.10 \%$ in eight chestnut varieties of Jiangxi Province. Liu et al. (2009) found that the average fruit set of SP was $11.32 \%$ in eight chestnut varieties of ebei Province. Zheng et al. (2013) also investigated that the uit set of SP was lower than $10 \%$ in six chestnut varieties of Liaoning Province. In the present study, we found that the fruit set of SP was $12.12 \%$ to $14.00 \%$ in 'Yanshanzaofeng', suggesting that self-sterility also existed in other chinese chestnut varieties. In addition, the size of the selfed seeds tended to be larger than that of the crossed seeds (Table 6, Fig. 7). Liao et al. (2014) reported a similar phenomenon in $C$. oleifera, possibly due to the greater availability of spatial resources for selfed seeds. In our case, the differences in pollen resource availability affected the fruit set and the number of seeds produced and even the size of the seeds in chestnut. One or two normal seeds are usually present in each selfed fruit (Table 4), which contrasts with the abundant developing seeds found in crossed fruit. The lower level of competition for nutrients and space makes a larger size possible in the selfed seeds of $C$. mollissima. It has been argued that pollen sources influence fruit set and seed production, as recorded in Cassia fasciculata (Martin and Lee, 1993) and Quercus ilex (Yacine and Bouras, 1997). Hence, several chestnut varieties that ensure adequate pollen sources should be planted together to decrease the probability of self-fertilization and improve the frequency of cross-fertilization in C. mollissima.

EARLY-ACTING INBREEDING DEPRESSION. EID can be an alternative explanation for the self-sterility syndrome associated with LSI (Júnior, 2017). EID is a strict postzygotic mechanism that occurs during seed formation and development 
(Valtueña et al., 2010), whereas postzygotic LSI results in abortion in a very short period after fertilization (Seavey and Bawa, 1986). Therefore, it is very difficult to distinguish which effects are attributable to postzygotic LSI and which are attributable to EID.

Variation in the size of normal selfed seeds and aborted seeds is usually regarded as one of the most important factors allowing the discrimination between EID and postzygotic LSI (Hao et al., 2012). It is assumed that LSI causes the uniform failure of self-fertilized ovules, whereas EID causes failure at various stages of development (Kiepiel and Johnson, 2014; Seavey and Bawa, 1986; Valtueña et al., 2010). There were no significant differences in normal seed characteristics following the SP and CP treatments (Table 6). However, we found that following SP, aborted seeds varied widely and continuously in terms of length (Figs. 6 and 7). The $\mathrm{CV}$ of the length of aborted selfed seeds ( $\mathrm{CV}=74.98 \%)$ was greater than that of $\mathrm{CP}$ seeds $(\mathrm{CV}=29.99 \%)$, indicating that SP caused abortion at different stages during seed development rather than at a uniform stage. LSI usually is thought to be controlled by a few genes, so the distribution of aborted seed sizes after SP should follow a clumped pattern (Nuortila et al., 2006). EID generally involves the expression of recessive deleterious genes at multiple loci and hence often leads to a wide range of aborted seed sizes (Hao et al., 2012; Hokanson and Hancock, 2000). Some similar cases also can be found in other species, in which several authors (Hao et al., 2012; Hokanson and Hancock, 2000; Nuortila et al., 2006) found that the selfed seed length exhibited a great deal of variation, which was thought to be consistent with the expectations of the EID hypothesis. Therefore, we support the view that EID occurs in C. mollissima and reject the possibility of complete postzygotic LSI.

\section{Conclusions}

In this work, we observed a reduction in fruit set following SP in chinese chestnut 'Yanshanzaofeng' and differentiated the processes leading to this reduction. The results reveal that the occurrence of self-sterility in C. mollissima can be explained by the existence of both prezygotic LSI and EID mechanisms.

\section{Literature Cited}

Botta, R., G. Vergano, G. Me, and R. Vallania. 1995. Floral biology and embryo development in chestnut (Castanea sativa Mill.). HortScience 30:1283-1286.

Chai, L.J., X.X. Ge, M.K. Biswas, Q. Xu, and X.X. Deng. 2011. Selfsterility in the mutant 'Zigui shatian' pummelo (Citrus grandis Osbeck) is due to abnormal post-zygotic embryo development and not self-incompatibility. Plant Cell Tissue Organ Cult. 104:1-11.

Fan, B.W. and S.J. Luo. 1993. A study on the percentages of fertile fruit of different cross combinations of chestnut varieties. Acta Agriculturae Universitatis Jiangxiensis 15:371-375.

Fan, X.M., D.Y. Yuan, J. Tang, X.M. Tian, X.H. Zhang, B.F. Wang, and X.F. Tan. 2014. Biological characteristics of flowering and pollination in Castanea henryi. Scientia Silvae Sinica 50:42-48.

Fan, X.M., D.Y. Yuan, J. Tang, X.M. Tian, L. Zhang, F. Zou, and X.F. Tan. 2015. Sporgenesis and gametogenesis in chinese chinquapin (Castanea henryi (Skam) Rehder \& Wilson) and their systematic implications. Trees 29:1713-1723.

Feng, Y.Q., Y.Y. Shen, L. Qin, Q.Q. Cao, and Z.H. Han. 2011. Short cakin 1, a novel mutant of Castanea mollissima, is associated with programmed cell death during chestnut staminate flower differentiation. Scientia Hort. 130:431-435.
Gao, C., D.Y. Yuan, Y. Yang, B.F. Wang, D.M. Liu, and F. Zou. 2015. Pollen tube growth and double fertilization in Camellia oleifera. J. Amer. Soc. Hort. Sci. 140:12-18.

Gibbs, P., M.B. Bianchi, and N.T. Ranga. 2004. Effects of self-, chase and mixed self/cross-pollinations on pistil longevity and fruit set in Ceiba species (Bombacaceae) with late-acting self-incompatibility. Ann. Bot. 94:305-310.

Gibbs, P.E. 2014. Late-acting self-incompatibility-The pariah breeding system in flowering plants. New Phytol. 203:717-734.

Guo, S.J. and F. Zou. 2014. Observation on the pistillate differentiation of chestnut (Castanea) cultivar Yanshanzaofeng. J. Chem. Pharm. Res. 6:686-690.

Hao, Y.Q., X.F. Zhao, D.Y. She, B. Xu, D.Y. Zhang, and W.J. Liao. 2012. The role of late-acting self-incompatibility and early acting inbreeding depression in governing female fertility in Monkshood, Aconitum kusnezoffii. PLoS One 10:e47034.

Hokanson, K. and J. Hancock. 2000. Early acting inbreeding depression in three species of Vaccinium (Ericaceae). Sex. Plant Reprod. 13:145-150.

Horsley, T.N. and S.D. Johnson. 2007. Is Eucalyptus cryptically selfincompatible? Ann. Bot. 100:1373-1378.

Ji, F.Y., W. Wei, Y. Liu, G.P. Wang, Q. Zhang, Y. Xing, S.H. Zhang, Z.H. Liu, Q.Q. Cao, and L. Qin. 2018. Construction of a SNP-based high-density genetic map using genotyping by sequencing (GBS) and QTL analysis of nut traits in chinese chestnut (Castanea mollissima Blume). Front. Plant Sci. 9:816.

Júnior, N.S.B. 2017. Evidence for post-zygotic self-incompatibility in Handroanthus impetiginosus (Bignoniaceae). Plant Reprod. 30:69-79.

Kakade, V., A.K. Dubey, R.M. Sharma, and S.K. Malik. 2017. Gametophytic self-incompatibility causes seedlessness in 'Kagzi Kalan' lemon (Citrus limon). J. Hort. Sci. Biotechnol. 92:303-312.

Kawagoe, T. and N. Suzuki. 2005. Self-pollen on a stigma interferes with outcrossed seed production in a self-incompatible monoecious plant, Akebia quinata (Lardizabalaceae). Funct. Ecol. 19:49-54.

Kiepiel, I. and S.D. Johnson. 2014. Breeding systems in Clivia (Amaryllidaceae): Late-acting self-incompatibility and its functional consequences. Bot. J. Linn. Soc. 175:155-168.

Liao, T., D.Y. Yuan, F. Zou, C. Gao, Y. Yang, L. Zhang, and X.F. Tan. 2014. Self-sterility in Camellia oleifera may be due to the prezygotic late-acting self-incompatibility. PLoS One 9:e99639.

Liu, J.F., Y.Q. Cheng, K. Yan, Q. Liu, and Z.W. Wang. 2012. The relationshuip between reproductive growth and blank fruit formation in Corylus heterophylla Fish. Scientia Hort. 136:128-134.

Liu, Q.X., G.P. Wang, and D.J. Kong. 2009. Study on the pollination and seed-setting characteristics of the main chestnut cultivars in Hebei Province. J. Hebei Agr. Sci. 13:11-12, 18.

Mahy, G. and A.L. Jacquemart. 1999. Early inbreeding depression and pollen competition in Calluna vulgaris (L.) Hull. Ann. Bot. 83:697-704.

Martin, M.E. and T.D. Lee. 1993. Self pollination and resource availability affect ovule abortion in Cassia fasciculata (Caesalpiniaceae). Oecologia 94:503-509.

Masahiro, N. 2003. Fertilization and In vitro growth of ovules in Japanese Chestnut (Castanea crenata Sieb. Et Zucc.). J. Jpn. Soc. Hort. Sci. 72:482-487.

McKay, J.W. 1942. Self-sterility in the chinese chestnut (Castanea mollissima). Proc. Amer. Soc. Hort. Sci. 41:156-161.

Nuortila, C., J. Tuomi, J. Aspi, and K. Laine. 2006. Early acting inbreeding depression in a clonal dwarf shrub, Vaccinium myrtillus, in a northern boreal forest. Ann. Bot. Fenn. 43:36-48.

Peralta, C.M., J.M. Guzmán, and M.C. Mandujano. 2014. How common is self-incompatibility across species of the herkogamous genes Ariocarpus. Amer. J. Bot. 101:530-538.

Pérez, P.F. and J.F. López. 2009. Usefulness of 13 morphological and phenological characteristics of sweet chestnut (Castanea sativa Mill.) for use in the DUS test. Euphytica 167:1-21.

Pound, L.M., M.A.B. Wallwork, B.M. Potts, and M. Sedgley. 2002. Early ovule development following self- and cross-pollinations in Eucalyptus globulus Labill. ssp. globulus. Ann. Bot. 89:613-620. 
Sage, T.L. and F.B. Sampson. 2003. Evidence for ovarian selfincompatibility as a cause of self-sterility in the primitive woody angiosperm, Pseudowintera axillaris (Winteraceae). Ann. Bot. 91:1-10.

Sage, T.L., F. Sterumas, B. Cole, and S.C.H. Barrett. 1999. Differential ovule development following self- and cross-pollination: The basis of self-sterility in Narcissus triandrus (Amaryllidaceae). Amer. J. Bot. 86:855-870.

Sage, T.L., M.V. Price, and N.M. Waser. 2006. Self-sterility in Ipomopsis Aggregata (Polemoniaceae) is due to prezygotic ovule degeneration. Amer. J. Bot. 93:254-262.

Seavey, S.R. and K.S. Bawa. 1986. Late-acting self-incompatibility in angiosperms. Bot. Rev. 52:195-218.

Shi, Z.G. and X. Li. 2010. Stigmatic morphology of chinese chestnut (Castanea mollissima Blume). HortScience 45:981-983.

Shi, Z.G. and R. Stösser. 2005. Reproductive biology of chinese chestnut (Castanea mollissima Blume). Eur. J. Hort. Sci. 70:S96-S103.

Simón-Porcar, V.I., A.D. Castro, M. Herrero, and J. Arroyo. 2015. Ovarian self-incompatibility in Narcissus papyraceus (Amaryllidaceae) is the result of a pre-zygotic response. Bot. J. Linn. Soc. 177:629-643.

Sogo, A. and H. Tobe. 2005. Intermittent pollen-tube growth in pistils of alders (Alnus). Proc. Natl. Acad. Sci. USA 102:8770-8775.

Streher, N.S., E. Guerra, R. Lüdtke, J. Semir, and J.H.A. Dutulh. 2018. Self-incompatibility in Habranthus gracilifolius (Amaryllidaceae): Pre- and post-pollination barriers. Braz. J. Bot. 41:375-384.

Tangitcharoen, S. and J.N. Owens. 1997. Pollen viability and pollen tube growth following controlled pollination and the relation to low fruit production in Teak (Tectona grandis Linn. f.). Ann. Bot. 80:401-410.

Thimmaiah, M.R., S.B. Choudhary, H.K. Sharma, A.A. Kumar, H. Bhandari, J. Mitra, and P.G. Karmakar. 2018. Late-acting selfincompatibility: A barrier to self-fertilization in sunnhemp (Crotalaria juncea L.). Euphytica 214:19.

Tomás, R.R., O.O. Ana, and J.A. Devesa. 1999. Reproductive biology in two Genisteae (Papilionoideae) endemic of the western Mediterranean region: Cytisus striatus and Retama sphaerocarpa. Can. J. Bot. 77:809-820.
Uylaşer, V., G. Yildiz, C. Mert, and Ü. Serdar. 2014. A general assessment of the candied chestnut industry in Turkey. Acta Hort. 1019:229-234.

Valtueña, F.J., R.R. Tomás, F. Espinosa, and O.O. Ana. 2010. Selfsterility in two Cytisus species (Leguminosae, Papilionoideae) due to early acting inbreeding depression. Amer. J. Bot. 97:123-135.

Vaughton, G., M. Ramsey, and S.D. Johnson. 2010. Pollination and late-acting self-incompatibility in Cyrtanthus breviflorus (Amaryllidaceae): Implications for seed production. Ann. Bot. 106:547-555.

Yacine, A. and F. Bouras. 1997. Self- and cross-pollination effects on pollen tube growth and seed set in holm oak Quercus ilex L (Fagaceae). Ann. Sci. For. 54:447-462.

Zhang, L., Q. Lin, Y.Z. Feng, X.M. Fan, F. Zou, D.Y. Yuan, X.C. Zeng, and H.P. Cao. 2015. Transcriptomic identification and expression of starch and sucrose metabolism genes in the seeds of chinese chestnut (Castanea mollissima). J. Agr. Food Chem. 63:929-942.

Zheng, R.J., D.Y. Wang, Z.P. Liu, and W.Z. Qu. 2013. Study on the pollination compatibility among the main chestnut cultivars in Liaoning province. J. Liaoning For. Sci. Technol. 3:15-16, 34, 36.

Zhou, Q.Y. and G.S. Liu. 2012. The embryology of Xanthoceras and its phylogenetic implications. Plant Syst. Evol. 298:457-468.

Zhu, C.C., G.M. Geng, J.Y. Zhou, and L. Liu. 2014. Analysis of chestnut industry development and trade patterns in the 21 st century. Nonwood For. Res. 32:184-191.

Zou, F., S.J. Guo, P. Xie, W.J. Lv, H. Xiong, and G.H. Li. 2013. Sporogenesis and gametophyte development in the chinese chestnut (Castanea mollissima Blume.). Taiwan J. For. Sci. 28:171-184.

Zou, F., S.J. Guo, P. Xie, H. Xiong, W.J. Lv, and G.H. Li. 2014. Megasporogenesis and development of female gametophyte in chinese chestnut (Castanea mollissima) cultivar Yanshanzaofeng. Intl. J. Agr. Biol. 16:1001-1005.

Zou, F., S.J. Guo, H. Xiong, J. Wang, X.N. Zhang, J.J. Peng, and Y.Q. Peng. 2015. Effects of different pollination treatments on nutrition changes of the ovary in chinese chestnut (Castanea mollissima Blume). Adv. J. Food Sci. Technol. 8:157-162. 